\title{
A MULHER, CENTRO DE RIQUEZA INOVADORA PARA O CONJUNTO DA SOCIEDADE *
}

\author{
Maria Olívia Dias **
}

O sociólogo, que se propõe analisar os universos inerentes à mulher, depara-se de imediato com a enorme diversidade de situações no campo teórico e prático, de tal modo que, pretender apresentar uma configuração completa da realidade, pode ser perigoso para o seu enquadramento nas práticas sociais emergentes na sociedade.

A história não tem sido muito explícita no reconhecimento de novas estruturas identificativas dos papéis das mulheres como grupos interagentes na sociedade. De facto, a sua presença como promotoras visíveis tem passado apagada no espaço social. Esta situação faz com que tenhamos de perspectivar esta comunicação com uma certa cautela.

Dito isto, achamos crucial analisar as expressões que pensamos estarem subjacentes à ideia básica, considerando-as como forças sociais activas do envolvimento da mulher e do seu contributo na sociedade.

Tratamos assim de quatro coordenadas significativas para a questão:

1. A mulher e a evolução social

2. A mulher e a dominação social

3. Os novos horizontes de integração social

4. A "área social mulher" como pólo de referência para os novos esquemas de integração social.

\section{A MULHER E A EVOLUÇÃO SOCIAL}

Enquanto capacidade para satisfazer as necessidades e aspirações, o paradigma da integração da mulher na sociedade, a nível individual, orienta-se para uma posição activa. Esta deveria, em certa medida, encontrar a nível colectivo o caminho intermédio entre os dois pólos de integração social, ou seja a natureza externa e a natureza interna ${ }^{1}$.

\footnotetext{
** Instituto Universitário de Desenvolvimento e Promoção Social — Pólo de Viseu da Universidade Católica Portuguesa.
} 
A natureza externa apropria-se de processos de produção e a natureza interna de processos de socialização. Com a evolução do sistema social, os processos de produção atingem os recursos naturais e mudam em valores o uso das energias, enquanto os processos de socialização educam os membros do sistema, tornando-os capazes de agir. A natureza interna e a natureza externa estão necessariamente em constante interacção e determinam a estrutura complexa das necessidades e das aspirações da sociedade global ${ }^{2}$.

Ora o equilíbrio do sistema social só existe quando no interior da sua estrutura os processos dinâmicos incluírem todos os comportamentos individuais e colectivos $^{3}$ e deste modo o grupo mulheres.

Existe, portanto, uma estreita ligação entre a qualidade das necessidades e das aspirações das mulheres, a evolução social e a estrutura dominante. Esta só poderá afirmar-se quando souber obter consenso do conjunto dos grupos sociais, dando resposta às necessidades imperativas e evitando uma eventual conflitualidade, susceptível de pôr em perigo o equilíbrio do sistema social.

Deste modo, a estrutura dominante deve espelhar a natureza das necessidades e das aspirações. Por conseguinte, as fortes modificações nas necessidades das pessoas obriga a modificações na estrutura dominante. Daqui deriva que a mulher, sendo parte integrante desse espaço, desempenha funções para o conjunto da sociedade, embora nem sempre reconhecidas.

Depois deste abstracto e sucinto reconhecimento de um modelo teórico interpretativo, pergunta-se: porquê e o que é para a mulher a evolução social deste fenómeno?

As respostas podem ser variadas. Procuraremos evidenciar algumas possíveis, sem que se pretenda que sejam definitivas.

Uma resposta que parece ser central diz respeito à necessidade de interpretar a condição da mulher no interior de uma teoria global do desenvolvimento social, salvaguardando ao mesmo tempo:

1) A especificidade das funções e da qualidade das necessidades.

2) O papel não subalterno, de protagonismo cultural e de agente histórico, substancialmente idêntico ao da condição masculina.

A nossa impressão é que as tentativas verificadas para interpretar a condição da mulher se têm sempre debatido com uma concepção rígida da sociedade, com certa lógica na interacção e dinâmica entre as diversas partes sociais, completamente externas e por isso suficientemente autónomas em relação à peculiaridade da condição feminina.

Isto é particularmente visível no caso da análise marxista que, pondo o esforço interpretativo na estrutura económica, não conseguiu oferecer à mulher um espaço autónomo, tanto na funcionalidade como na disfuncionalidade, em relação à evolução social. 
Mas, isto é também típico de toda e qualquer concepção sociológica global que, ao assumir as relações de poder, a dinâmica das classes sociais, a circulação das elites e dos grupos sociais, o núcleo central da interpretação da realidade social acabou por fazer uma leitura parcial, descurando o âmbito do protagonismo cultural da mulher.

Pensamos que seja esta uma das consequências dos efeitos de distorção que a estrutura dominante provoca nos modelos interpretativos, cuja lógica de referência se situa nos equilibrios e na circularidade das relações que ligam as diversas partes do sistema social.

Uma aproximação de tipo sistémico é-nos dada por Habermas ${ }^{4}$, onde o subsistema sociocultural (sistemas culturais e os valores de referência, tradições culturais, instituições de socialização e de profissionalização com força normativa) assume como referência a natureza interna, enquanto o subsistema económico (instituições económicas, organização das forças produtivas, tráfego comercial, utilização dos recursos naturais) a natureza externa. O subsistema político-administrativo marca as suas características na estrutura dominante. $\mathrm{Na}$ medida em que as instituições políticas consigam concretizar efectivamente uma determinada estrutura dominante, o sistema social pode envolver e ampliar os próprios objectivos de crescimento. De outro modo continuará sempre no abstracto.

É com base nesta teoria sistémica de Habermas que se procura substituir aquela concepção das relações, entre as diversas partes do sistema de tipo normativo (existência de um único pólo de referência capaz de irradiar regras, normas e orientação que têm um efeito constringente para todos os outros elementos), por uma concepção "adaptativa" que pressupõe a existência de diversos pólos todos iguais, capazes de interagir reciprocamente, todos dotados de autonomia, todos em grau de determinar potencialidades condicionantes para o sistema.

É assim que uma posição de subalternidade e de marginalidade, como o caso da mulher, aparece estruturalmente reversível à luz dos maiores modelos interpretativos que amadureceram com a sociedade industrial. Esses modelos não podem deixar de ter em conta "inputs" de controlo e de inovação, a não ser que neguem à condição feminina as qualidades de especificidade, autonomia, capacidade de orientação em relação à qualidade das necessidades, à configuração das mulheres como grupo social e agentes históricos de uma visão própria do mundo, em interaç̧ão com a visão dos outros grupos sociais.

Fechamos aqui este parêntese, o qual pode provocar equívocos. No entanto, temos consciência de que o esforço interpretativo deve necessariamente dirigir-se à situação de marginalização das mulheres e tentar individualizar os mecanismos que lhe estão na origem, mesmo numa aproximação de tipo sistémica que se baseia na capacidade paritária da interacção de cada uma das partes do sistema. 


\section{A MULHER E A DOMINAÇÃO SOCIAL}

Por dominação entendemos, segundo E. Boulding, o poder com manifestações estruturais ${ }^{5}$. De facto, um forte impulso foi dado em relação ao processo de visibilidade social da mulher com o crescimento e desenvolvimento de uma maior consciencialização no que concerne à dominação, no sentido indicado.

O despertar da consciência das mulheres nas últimas décadas, não só como cidadãs com direitos iguais, mas também o descobrirem-se como portadoras de força e capacidade de intervenção social, faz com que apareçam certos movimentos na sociedade, onde os conceitos recorrentes evoluem dando novos significados aos papéis da mulher. É exactamente a estrutura de dominação que se apresenta com capacidade de envolver o conjunto de recursos e energias dos diferentes grupos sociais, em função da realização de objectivos tais como a qualidade das necessidades e das aspirações que caracterizam o sistema social.

Porém, é preciso remontar longe na história para encontrar uma posição da mulher, que seja manifestamente activa e promotora de modelos de comportamento.

Certamente, é no interior da estrutura dominante, fundada no sistema de parentesco, com a família alargada, que ainda hoje é reconhecida à mulher uma grande capacidade criativa e uma posição central no sistema social.

No entanto, com o alargamento das comunicações sociais e da mudança social, torna-se insuficiente a dominação do sistema de parentesco, tornando-se incapaz de emanar modelos de comportamento com capacidade para absorver a crescente complexidade da sociedade.

Mas parece-nos que a estrutura dominante não pode deixar de se basear num consenso - activo e passivo - de todas as forças sociais e de realizar em cada momento um equilíbrio que, por natureza, tenha em conta a especificidade de cada uma das simples partes do sistema e da circularidade das relações entre si. A sociedade, que é composta por todos os membros, faz com que o desenvolvimento do sistema social se prenda com todos eles nos seus aspectos quantitativos e qualitativos.

Sendo assim, reconhecendo-se a importância da mulher como riqueza para a sociedade, não podemos deixar de atribuir o seu atraso à debilidade que ainda hoje verificamos na evolução e na dominação social. Esta situação pode ser explicada fundamentalmente por alguns aspectos: interesse masculino, efeitos da socialização, lentidão dos processos, percepção feminina e percepção da comunidade social.

É evidente que, tendo em conta os interesses masculinos, não é fácil que o homem ceda espontaneamente às exigências femininas, o que não tira que alguns se possam revelar inclinados para um redimensionamento das suas atitudes e pontos de vista. Mas, de um modo geral, as coisas não se têm verificado neste sentido. Mesmo os chamados revolucionários, embora aspirando a uma nova ordem, 
não avançaram com propostas particulares em ordem à criação de um novo espaço para uma nova concepção de mulher. Assim, a mulher encontra grande dificuldade porque as estruturas familiar e social não mantêm atitudes iguais. Enquanto o homem tem uma atitude de tipo tradicional e a sociedade ainda está orientada nesse sentido, são desvalorizadas as capacidades femininas.

Na mesma linha, o efeito da socialização tem as suas vantagens, mas também apresenta desvantagens. $O$ facto desta morosidade deve-se essencialmente à socialização, que implica uma formação dos agentes que, uma vez culturalizados ${ }^{6}$, dificilmente estão dispostos a mudar. É evidente, todavia, que uma socialização mais adequada pode proporcionar uma mudança, em particular na evolução da condição da mulher, de modo que possa progredir no desenvolvimento e dar resposta a exigências fundamentais, não só a nível pessoal mas também social. Convém que a socialização se adapte a novas realidades mas, para isso, os agentes socializadores ${ }^{7}$ devem procurar satisfazer, com o seu contributo, a mudança da condição da mulher. Para uma maior abertura e progresso na mudança é indispensável a flexibilidade.

Por outro lado, o visco cultural prende-se com a lentidão dos processos e a neutralização das novas tendências, colocando a mulher em desvantagem. De facto, a complexidade dos processsos nas mudanças sociais torna-os normalmente lentos. Abandonar velhos modelos, para dar lugar aos novos, exige tempo de interiorização, de modo que sejam aceites, o que requer não só muito tempo mas também boa vontade para se superarem certas acções contrapostas pelas mulheres.

Mas também a percepção das mulheres condiciona muitas vezes o evoluir da sua condição. Queremos com isto dizer que, se a situação continua neste estado, deve-se também ao facto de grande parte das mulheres não mostrar interesse, antes certa apatia na defesa dos seus direitos. Mais grave é transmitirem às novas gerações os mesmos esquemas de subordinação. Com tudo isto, é normal que o processo seja lento.

Por fim, a percep̧̧ão da comunidade, ou seja o lento processo a que ainda assistimos, deve-se em parte à herança colectiva, como um dado cultural, mas também subcultural ${ }^{8}$, que não desaparece facilmente, dado que foram herdadas muitas condições que se encontram enraizadas na mentalidade das pessoas, com muitos símbolos criados culturalmente, através das instituições políticas, económicas, e religiosas, que tendem a perpetuar-se devido ao descuido e ao pouco interesse da sociedade pela problemática da condição da mulher.

Destas breves achegas podemos concluir que a mulher ainda tem razões de sobra para se queixar ${ }^{9}$, para continuar a reivindicar os seus legítimos direitos. Há, de facto, muito para mudar. Se as mulheres ainda lutam, não só por valores económicos, mas também por um maior respeito humano e pelo reconhecimento como seres humanos, têm direito a satisfazer as suas exigências materiais, familiares, sociais e espirituais ainda não satisfeitas. 


\section{OS NOVOS HORIZONTES DE INTEGRAÇÃO SOCIAL}

Por integração social entendemos a pré-disposição activa do indivíduo, dos recursos ambientais e colectivos que são necessários à satisfação das necessidades das pessoas.

A sociedade onde vivemos evolui para novas formas de integração social. A condição da mulher caminha neste sentido, pois escolhe deliberadamente novas perspectivas. Isto é, renuncia à análise da quantidade e da qualidade dos condicionamentos negativos, que se foram determinando e acumulando sobre si ao longo da história, considerando mais produtivo concentrar a atenção nos processos emergentes das novas formas de integração social.

Não queremos com isto desvalorizar - com uma simples passagem de esponja - toda uma história que reduziu ou nunca exaltou, no sentido de uma originalidade autónoma, as oportunidades de promoção da mulher. Mas é nossa convicção encontrar todos os actores e instituições no ponto de partida para construir um futuro, tornando-se preciosa a acumulação histórica do que se viveu, em função da sua projecção operacional e perspectiva, tratando-se ou não de momentos de sucesso, de prestígio ou gratificação.

Assim, a sociedade segue de perto novos horizontes da integração social, sendo possíveis algumas análises da situação da mulher.

Primeiro, a distância que objectivamente a separa do acesso aos mínimos de satisfação de novas necessidades.

Segundo, o potencial de recursos, de valores e de vitalidade que a área social mulher é capaz de oferecer à sociedade, porque os novos horizontes da integração social traduzem-se em modelos de comportamento, orientações valorativas e fórmulas institucionais válidas para o conjunto da formação social.

\section{A "ÁREA SOCIAL MULHER" COMO PÓLO DE REFERÊNCIA PARA OS NOVOS ESQUEMAS DE INTEGRAÇÃO SOCIAL}

Nesta parte residirá essencialmente o mérito desta comunicação, tentando uma primeira aproximação ao potencial de recursos, de valores e de vitalidade que a "área social mulher" pode oferecer à sociedade, para que os novos horizontes da integração social se traduzam em modelos de comportamento válidos para o conjunto da colectividade.

1. Encontramo-nos ainda numa fase histórica em que a principal tensão da mulher se orienta para o esforço gravoso e por vezes proibido de libertação de algumas estruturas sociais que a oprimem e inibem, em relação a uma produção cultural autónoma. 
2. É típico da natureza humana - em relação à qual as mulheres constituem um dos grupos sociais mais atingidos - encontrar nesta fase grandes dificuldades de autocompreensão, de agregação e de consequente individualização de estratégias operativas para a afirmação, no seio da sociedade, dos valores de que são portadoras.

Não se trata de instaurar novas divisões entre homem e mulher, encontrando fórmulas de integração social válidas só para as mulheres, mas de considerar formas de integração idênticas, tratando-se de homens ou de mulheres. No entanto, tais formas podem ser atingidas através de diversos itinerários que são mais ou menos consensuais à especificidade das duas condições.

A nossa posição é a de que este caminho específico da promoção da mulher não seja procurado só de modo a garantir e a manter uma posição activa no plano das escolhas e dos valores a atingir, mas que os itinerários permitam a toda a sociedade um salto qualitativo do desenvolvimento social.

\section{a) O direito ao protagonismo social}

É necessário que o conjunto da sociedade tome como guia e orientação alguns valores que emanam da "área social mulher". Neste sentido não se trata de construir novos modelos de organização social "para a mulher", mas de construir uma nova sociedade "com a mulher", como pólo de referência e como protagonista.

Esta tentativa de individualização dos bens, resposta que a área social pode oferecer a toda a sociedade, tem um carácter metodológico e exemplificativo e parte da análise da situação actual do desenvolvimento social, reconhecendo ao espaço da mulher recursos decisivos para toda a sociedade.

As escassas possibilidades na participação social, cultural e política que objectivamente a sociedade oferece à mulher fazem parte de uma ampla e vasta literatura consolidada, conhecida por todos nós, mas que não pretendemos desenvolver nesta comunicação.

Aquilo que nos interessa sublinhar não é tanto o aspecto relacionado com os recursos e a mobilidade atribuída à mulher quanto ao conteúdo dos papéis tradicionais de mulher, esposa e mãe, mas a desatenção e a falta de valorização social em relação a esses papéis.

O verdadeiro problema é que a sociedade se projecta para a dominação económica que tem como valores essenciais a eficiência produtiva, a circulação e o consumo dos bens materiais, a estrutura hierárquica das relações e das funções sociais e portanto a legitimação do princípio da selecção e da competitividade. A condição da mulher na sociedade é considerada quase e só como funcional. Sendo assim, torna-se difícil exercer uma renovação ou mudança mais visível em relação à organização social, atribuindo-se-lhe um papel passsivo. 
Sendo desta natureza o processo em que a mulher está investida, isto faz com que se insista em considerar que o primeiro problema a eliminar não é tanto a garantia de determinadas estruturas sociais, mas a atenção e a valorização das potencialidades e riqueza que possui e pode dar à sociedade.

É necessário uma revolução cultural, que pensamos já sólida nalguns países e regiões, mas ainda mal iniciada noutras.

No caso da mulher é difícil individualizar os factores que determinaram e acalentaram a pressão da dominação económica. Torna-se mais evidente a subalternidade dos papéis femininos com a redução da família ao modelo "nuclear", a rígida divisão dos papéis e por isso a estranheza total da mulher na dominação do desenvolvimento social, sector económico privilegiado com possibilidade de incidir também nas formas de participação no protagonismo cultural e político.

Quanto aos factores atenuantes da pressão exercida na transmissão dos valores e na imposição de papéis da parte da dominação económica, verifica-se um conjunto de elementos diversos que provavelmente produziram e continuam a acumular tensão no mesmo grupo das mulheres ${ }^{10}$.

Podemos dizer que intervieram simultaneamente:

1) O mesmo processo de escolarização, embora gradual, tem vindo a envolver quase todas as mulheres.

2) Embora lentamente, tem-se concretizado conscientemente alguma suspensão da escravidão da mulher doméstica.

3) A campanha intensa dos "mass media" que produziram uma "transparência" das condições de vida, com efeitos no plano da sensibilização para a justiça social e igualdade de oportunidades de participação.

4) A revolução sexual que certamente empobreceu a civilização, mas que teve o mérito de relegar para "sedes exclusivas e reservadas" os comportamentos masculinos patológicos (derivados de uma má atitude sexual da nossa geração), que condenam a mulher a um papel imposto e humilhante.

5) O difundir da informação e do conhecimento em relação à vida sexual e à maternidade, com efeitos sobre uma escolha autónoma, não só dependente do médico, do marido, do pai, da sociedade, mas onde também a mulher exerce a sua intervenção e participação.

Estas são algumas das componentes mais importantes que determinaram o grupo social das mulheres e que atenuam o princípio de dominação económica do desenvolvimento.

Mesmo assim, nalguns casos, a mulher continua à margem do mercado de trabalho e, quando isto não acontece, a sua eventual participação é de carácter subalterno em relação ao homem, privada em certa medida das conotações ligadas à carreira profissional, à indispensabilidade e à prioridade, que qualificam a força de trabalho do homem. 
Por conseguinte, o "grupo mulheres" é o grupo menos envolvido nos valores de referência na sociedade, ao menos em relação à dimensão do trabalho considerado central no protagonismo social.

Daqui resulta a exigência de uma alteração na dominação. Se hoje cresce e se impõe um consenso generalizado para redimensionar o princípio da prioridade da economia e recuperar a dimensão humana da vida social, será necessário construir um protagonismo social eliminando velhos esquemas que prejudicam o desenvolvimento económico.

Neste sentido, e de um modo justo, as mulheres têm reivindicado o reconhecimento da participação e do protagonismo político e cultural fundado não só nos pressupostos da democracia do Estado de direito, mas também na caracterização que tem dominado a economia e que tem marcado a vivência deste grupo social.

É sobretudo numa projecção na perspectiva do desenvolvimento social que o direito das mulheres ao protagonismo representa uma das novas fronteiras de integração social. Mas o protagonismo, além de não poder ser funcional, não reveste só um aspecto de mecanicidade e automatismo mais ou menos garantidos, mas orienta-se para a valorização de uma prestação específica, genuína, à capacidade do grupo-mulher em incidir na mudança e na inovação do desenvolvimento social.

Esta motivação das mulheres ao protagonismo cultural processa-se paralelamente com a capacidade deste grupo social se mover e radicar os próprios valores no sistema social.

O defender-se hoje este protagonismo, dos efeitos perversos da dominação económica constitui um património real das mulheres e uma qualidade indispensável para a realização de novas metas de integração social ${ }^{1 !}$.

O protagonismo cultural das mulheres é, portanto, uma condição imprescindível ao desenvolvimento social, se a sociedade quiser conquistar um novo tipo de desenvolvimento.

Assim, pensamos que os valores de referência, o viver quotidiano, a cultura das mulheres, pela importância que têm para a natureza interna do sistema, devem poder passar através de adequados canais de participação política e social e constituir o núcleo central do novo projecto de desenvolvimento.

Paradoxalmente, podemos afirmar que só uma sociedade, também à medida da mulher, está em condições de garantir o direito ao protagonismo social a partir do momento em que, valorizando o seu contributo, poderá pôr fim ao princípio de funcionalidade à dominação económica das experiências individuais e colectivas.

As mulheres são ao mesmo tempo as mais próximas da natureza interna do sistema e as mais afastadas dos esquemas de participação social e política, esquemas que se reflectem ainda nos valores da sociedade actual.

A garantia da incidência das mulheres no desenvolvimento social comporta necessariamente transformações mais radicais da nossa sociedade, tanto no sen- 
tido de uma mudança da dominação, como no da predisposição para novas estruturas de protagonismo cultural e social.

\section{b) O trabalho compatível}

Passando a um outro campo, o da participação no trabalho, vejamos como também aqui é possível encontrar algumas propostas que provêm da "área social mulher" e que tornam possível a realização de novas formas de integração social.

A sociedade, caracterizada por uma concentração das forças de trabalho institucionais na categoria dos homens, exclui as mulheres. Todavia, a relativa exclusão do mercado de trabalho parece não advir exclusivamente de uma orientação rígida das respectivas motivações para sectores de interesse externos à actividade laboral (como por exemplo, a família, a universidade, o tempo livre), mas acentua-se mais devido ao elevado custo do trabalho institucional, que tem determinado uma estratégia de contenção da base produtiva e de uma óptima utilização da parte das forças patronais.

De facto, o fenómeno da ocupação feminina é o melhor indicador, a este propósito.

Mais grave é serem excluídas do trabalho institucional, mas desenvolverem um trabalho dividido e oculto no mercado de trabalho.

Parte das formas de participação no trabalho, que é central para a mulher, se, por um lado, resolveu o problema das compatibilidades entre papéis diferentes, por outro, permitiu um forte alívio para os patrões através do aumento do trabalho oculto.

De considerar também que a compatibilidade entre diversos papéis sociais realiza-se em tempos sucessivos e não contemporânea ou paralelamente ao longo de toda a vida. A sua divisão do trabalho corresponde a:

- uma divisão entre participação no trabalho e outros papéis sociais;

- uma divisão entre população em situação de trabalho e população fora do mercado de trabalho.

Por outras palavras, a assunção de outros papéis, por exemplo a família, corresponde à expulsão do mercado de trabalho institucional e realiza-se necessariamente em tempos diacrónicos e não em tempos sincrónicos.

É, portanto, a este nível que parece importante pôr-se a tónica da participação desigual do "grupo social mulheres" nas estruturas produtivas da sociedade; e é a este nível que deve ser posto o problema do grau de satisfação no trabalho.

Aos elementos de rigidez e de compartimentação que ainda caracterizam o princípio da racionalidade, como lógica do desenvolvimento da sociedade, con- 
trapõem-se de maneira crescente elementos de flexibilidade e modulação na conformação dos tempos e na mesma prestação de trabalho que tendem a recuperar:

- os espaços da liberdade e das escolhas individuais.

- e uma maior harmonização das exigências produtivas e das necessidades.

A consecução de novas e mais avançadas formas de integração social, no campo da participação e da satisfação do trabalho, parece depender de uma modificação da relação pessoa-prestação de trabalho, no sentido de predisposição para oportunidades que tendam a garantir uma maior participação da mulher no processo produtivo, nos tempos e na natureza que convêm às suas exigências.

Por conseguinte proceder-se-ia, então, à passagem do trabalho dividido ao trabalho compatível, na base do princípio organizativo do sistema social que não privilegia o lucro económico máximo (através da concentração do trabalho nos tempos e grupos sociais rígidos), mas promove a riqueza dos diversos papéis sociais, através de uma possível explicação contextual e atingindo o objectivo de uma interacção constante entre eles.

A possibilidade de agir, com uma margem suficiente de liberdade nos diversos papéis sociais (trabalho manual, intelectual, família, educação, cultura, tempos livres, relações interpessoais), constituiria um benefício para a totalidade dos indivíduos da sociedade e permitiria superar a divisão do trabalho. Isto, não tanto no interior das empresas, mas sobretudo entre os grupos sociais "concentrados no mercado de trabalho" e grupos sociais "guetizados" noutros papéis sociais. Uns e outros desligados e distantes, igualmente alienados numa sociedade feita de compartimentos que não é capaz de recompor a sua verdadeira identidade

\section{c) O reequilíbrio entre "status" e "papéis"}

Uma outra necessidade à qual a sociedade deve dar, necessariamente, uma resposta é a de atingir um novo e justo equilíbrio entre "status" e "papéis"12.

Assim, hoje encontramo-nos numa situação na qual existe a descompensação entre estes dois pólos de comportamento indivíduo-sociedade, que deve ser corrigida.

Há grupos sociais aos quais a sociedade exige muito e grupos sociais aos quais não exige quase nada. Por outro lado, há grupos sociais que possuem um "status" bastante rico e que não podem dar nada à sociedade, porque esta não lhes pede esta prestação, e há outros grupos sociais que, ao contrário, têm um "status" pobre e disperso, aos quais a sociedade exige muito.

As mulheres têm enormes riquezas do ponto de vista de modelos de comportamento, de valores de referência, de recursos, de energias para uma afirmação na sociedade. No entanto, esta pede-lhes pouco, prefere que continuem "guetizadas" 
na escola, na família, sem participar na gestão política e nos centros vitais do desenvolvimento social, todos concentrados no mercado de trabalho ${ }^{13}$.

As mulheres tiram desta enorme dispersão de papéis um "status" pobre; ou seja, acabam por ter uma capacidade de dar que é extremamente reduzida porque, pelo facto de se perderem em tantos papéis indefinidos, não encontram uma identidade e um "status" apropriados ${ }^{14}$.

Uma nova organização da sociedade deve então responder a esta necessidade e reequilibrar os papéis e os "status"; deve pôr a mulher em condições de dar aquilo que ela pode dar, através dos pedidos que sejam adequados às suas potencialidades de riqueza.

Só assim a sociedade responderá e encontrará o equilíbrio entre natureza interna e natureza externa, de que falámos, porque só assim estará em condições de acolher o "grupo mulheres" e toda uma série de problemáticas que são centrais para o funcionamento do sistema.

Posto isto, uma sociedade que se preocupe em dar espaços suficientes a este grupo, que tem um "status" muito rico, reequilibrará necessária e automaticamente a relação entre natureza interna e natureza externa.

\section{Conclusão}

Os casos que apresentámos, sobretudo os três últimos pontos (protagonismo social, trabalho compatível e o equilíbrio entre "status" e "papéis"), são só alguns exemplos específicos que a mulher não pode deixar de seguir para uma satisfação activa das próprias aspirações.

Os exemplos poderiam multiplicar-se, no entanto o tempo que temos à disposição não nos permite, aqui, um maior aprofundamento. Demos algumas achegas muito rápidas que, no entanto, podem ser suficientes para nos permitir antever outros estímulos possíveis e outras riquezas que a "área social mulher" é capaz de produzir:

1) Alguns modelos de rotatividade são preconizados para superar o problema da rejeição ao trabalho desqualificado, desmotivante e de grande stress para a mulher.

2) A capacidade da mulher, em manter os conflitos da mudança paritária no plano horizontal, sem recorrer a hierarquias, solucionando problemas e operando um salto qualitativo no sentido da qualidade de vida e da recuperação da autenticidade das relações humanas.

3) A tenacidade com que as mulheres rejeitam os papéis tradicionais de subalternidade é uma riqueza valiosa que hoje o sistema possui para realizar um salto qualitativo nas relações. 
4) A crise que vivemos actualmente, no que se refere ao modelo de política social, fundado na standardização das prestações e na burocratização das relações interpessoais, às quais se opõe uma estrutura de necessidades da sociedade, fortemente articulada na centralidade da dimensão humana e a recuperação do seu sentido, é um sintoma da necessidade do sistema social em descobrir riquezas e valores específicos da "área social mulher".

Estes e outros exemplos representam a chave interpretativa da condição sociológica de uma sociedade que pode tirar elementos de inovação social e novos esquemas de organização social, bem como objectivos mais qualitativos e avançados de identificação colectiva, quando não descurar os valores e modelos de comportamento que provêm da "área social mulher".

Será uma "sociedade com a mulher como centro propulsor das riquezas e das referências colectivas", o que poderá levar a novos horizontes de integração social.

\section{NOTAS}

* Comunicação apresentada no Seminário "Portugal e a União Europeia - As Mulheres e a Igualdade de Oportunidades", promovido pelo Ministério do Emprego e da Segurança Social em conjunto com o CIDM (Comissão para a Igualdade e para os Direitos das Mulheres), realizado em Maio de 1995.

' Por natureza externa entendemos os recursos materiais não humanos do ambiente, os instrumentos de produção e os seus modelos organizativos (o ambiente geográfico, o habitat, a especialização $\mathrm{e}$ a inovação). Por natureza interna, entendemos o substracto orgânico dos membros da sociedade, o conjunto dos valores e das normas que regulam as relações interpessoais, o património dos usos e costumes que constituem a matriz sociocultural.

${ }^{2}$ Entendemos como sociedade global a colectividade das pessoas juntamente com as posições e os papéis que aí desempenham.

${ }^{3}$ GHOMBART, P.H.l., Pour une Sociologie des aspirations, Paris, Denoel-Gouthier, 1965.

${ }^{4}$ HABERMAS, J., La crisi della razionalità nel capitalismo maturo, Roma, Laterza, 1975. Apresenta-nos esquematicamente o sistema social em três subsistemas sociocultural, económico e político administrativo.

${ }^{5}$ BOULDING, Elise, The Underside of History, New York, Halsted Press, 1992. ONU, Femmes dans le monde, 1970-1990:Tendances et statistique, New York, Nations Unies, 1991.

${ }^{6}$ Esta dificuldade associa-se, muitas vezes, ao facto de as mães, empenhadas em trabalhos fora de casa, confiarem a educação e a assistência dos filhos às avós, tornando-se mais difícil, mais insegura a socialização das novas gerações, dado que a tendência é a transmissão dos mesmos usos e costumes, tornando-se difícil a socialização da mulher em termos de concretização de um processo diferente.

${ }^{7}$ A sua função, tanto pode ser positiva como negativa, mas é evidente que os meios de comunicação social se apresentam muitas vezes ambivalentes quanto ao conteúdo das mensagens transmitidas. Mesmo provindo das mesmas fontes, as correntes de opinião são divergentes, 0 que não facilita antes impede que se progrida.

${ }^{8}$ Entendemos por subcultura as concepções e as suas implicações culturais, respectivamente do homem e da mulher. 
${ }^{9}$ Mas, temos de reconhecer que só o facto de as pessoas sentirem isto já é um sinal positivo, pois revela que começam a perceber que ainda há desigualdades que é preciso combater para as eliminar. Não se pretendem soluções de tipo selvagem, mas respostas mais claras e humanas, através de uma mudança adequada e comprometedora.

${ }^{10}$ AA.VV., International Study of Discrimination and Participation, London, University of Bath, 1992, passim; BIANCHINI, A., Voce di donna, Milano, Bompiani, 1978, pág.32 e ss.; EVANS, M, The Women Question, London, University of Kent, ${ }^{2} 1993$.

"FONSECA, A., "Le donne nel mondo di oggi e di domani", Civiltà Cattolica, 3361, 1990, pp. 368-381; MILES, R., The Women's History of the World, London, Palladin, 1990; ONU, Femmes défis pour l'an 2000, New York, Nations Unies, 1991.

12 MYRDAL, A. e KLEIN, V., Women's Two Roles. Home and Work, Routledge e Kegan Paul Lda. ${ }^{2} 1968$; RODRIGUES, J.A. de, "Continuidade e mudança nos papéis das mulheres urbanas portuguesas: emergência de novas estruturas familiares", Análise Social, Vol. XIX, 1983, pp. 909-938.

${ }^{13}$ KAREN, O. M., The Status of Women, London, Rokefeller Foudation, 1984, p. 41 e ss.; FIGES, E., Il posto della donna nella società degli uomini, Milano, Feltrinelli, 1970, passim.

${ }^{14}$ DIAS, M. O., "Influxos da transformação do "status" e do "papel" da mulher sobre a natalidade", Gestão e Desenvolvimento, 1, Viseu, UCP, 1992, pp. 59-86; COWAN, N.L., "Methodological Study of Sex Stereotypes", Sexes Roles, 3, 1977, pp. 205-206.

\section{BIBLIOGRAFIA}

AA.VV., 1992, International Study of Discrimination and Participation, London, University of Bath.

BIANCHINI, A., 1978, Voce di donna, Milano, Bompiani.

BOULDING, E., 1992, The Underside of History, New York, Halsted Press.

COWAN, N. L., 1977, "Methodological Study of Sex Stereotypes", Sexes Roles, 3, p. 205-206.

DIAS, M. O., 1992, "Influxos da transformação do "status" e do "papel" da mulher sobre a natalidade", Gestão e Desenvolvimento, vol. 1, Viseu, UCP, p. 59-86.

EVANS, M., ${ }^{2} 1993$, The Women Question, London, University o Kent.

FIGES, E., 1990, ll posto della donna nella società degli uomini, Milano, Feltrinelli.

FONSECA, A., 1990, "Le donne nel mondo di oggi e di domani", Civiltà Cattolica, 3361, p. $368-381$.

GHOMBART, P. H. I., 1965, Pour une sociologie des aspirations, Paris, Denoel-Gouthier.

HABERMAS, J., 1975, La crisi della razionalità nel capitalismo maturo, Roma, Laterza.

KAREN, O. M., 1984, The Status of Women, London, Rokefeller Foudation.

MILLES, R., The Women's History of the World, London, Palladin.

MYRDAL, A. e KLEIN, V., ${ }^{2} 1968$ The Women's Two Roles. Home and Work, Routledge e Kegan Paul Lda.

ONU, 1991, Femmes dans le monde, 1970-1990: Tendances et statistique, New York, Nations Unies.

RODRIGUES, J. A. de, 1983, "Continuidade e mudança nos papéis das mulheres urbanas portuguesas: emergência de novas estruturas familiares”, Análise Social, Vol.XIX, pp. 909-938. 